\title{
MÚLTIPLAS VISÕES SOBRE AS ATIVIDADES DE TRABALHO REMUNERADO, DESENVOLVIDAS POR DETENTOS NA PENITENCIÁRIA ESTADUAL DE MARINGÁ
} MULTIPLE FOCUSES ON THE REMUNERATED WORK ACTIVITIES, DEVELOPED IN THE STATE PRISON OF MARINGÁ

\section{Alfredo Lopes da Costa Moreira Neto}

Mestre em Administração pelo PPA - UEM/UEL - Universidade Estadual de de Maringá/ Universidade Estadual de Londrina

\section{Maria Iolanda Sachuk}

Prof. do Departamento de Administração da UEM - Universidade Estadual de Maringá
Recebido em: 09/12/2010 Aprovado em: 25/03/2011

\section{RESUMO}

O objetivo deste artigo foi compreender as múltiplas visões sobre as atividades de trabalho remunerado, desenvolvidas na Penitenciária Estadual de Maringá - PEM. Discussões sobre o papel do trabalho prisional, sob a ótica dos detentos que exercem atividades de trabalho dentro das penitenciárias; daqueles que os acompanham, controlam e supervisionam seu trabalho; bem como daqueles responsáveis pelos programas de atividades de trabalho implementados internamente, não são comuns na literatura das ciências sociais aplicadas, justificando, então, a realização deste estudo. A pesquisa é descritiva, qualitativa, corte transversal, interpretada com base na hermenêutica, alicerçada no conceito de vita activa de Hannah Arendt e sobre os sentidos do trabalho. Concluiu-se que, para os envolvidos direta e indiretamente nas atividades de trabalho remunerado desenvolvidas pelos presos na PEM, o trabalho é de fundamental importância, não só para o preso, mas também para o alcance dos objetivos da instituição penal lócus da presente pesquisa.

Palavras-chave: atividades remuneradas, significado do trabalho, trabalho prisional.

\section{ABSTRACT}

The objective of this article was to understand the multiple focuses on the remunerated work activities, developed in the State Prison of Maringá - PEM. Discussions on the role of prison work, under the optics of the prisoners who develop these work activities in the prisons; of those who accompany, control and supervise their work; as well as of those responsible for the programs of work activities implemented internally, are not common in the literature of applied social sciences, justifying, therefore, the accomplishment of this study. This research is descriptive, qualitative, transversal cut, interpreted hermeneutically, based on the concept of Active Vita of Hannah Arendt and on the meanings of the work activities. It could be concluded that for people involved directly and indirectly in the remunerated work activities developed by the prisoners in PEM, the work is essential, not only for the prisoners, but also for the accomplishment of the researched criminal institution aims/objectives.

Keywords: remunerated activities, meanings of the work activities, prison work. 


\section{INTRODUÇÃO}

A inclusão do trabalho no processo de ressocialização e reeducação do preso, hoje em dia, consiste em discussão de relevância como proposta de formação profissional do detento, eliminação da ociosidade e manutenção dos princípios de recuperabilidade em um nível importante de segurança e exequibilidade. Segundo Silva (2001), o principal segmento das prisões é constituído de pessoas provindas dos segmentos mais pobres da sociedade, cujos sujeitos geralmente apresentam baixa escolaridade, célula familiar desestruturada, desqualificação profissional e participação precária no mercado de trabalho, dentre outras características que dificultam sua inserção na sociedade, quando conseguem a liberdade.

As diferentes formas, no Brasil, de utilização de mão de obra carcerária podem advir de quem cumpre pena em regime fechado, a partir de trabalho a ser realizado dentro das unidades penais; ou fora, no caso da realização de obras públicas; e em regime semiaberto, nas penitenciárias industriais, penitenciárias agrícolas e trabalhos externos para empresas privadas e outras entidades, sendo que na PEM - Penitenciária Estadual de Maringá - isso ocorre na primeira situação, ou seja, para quem cumpre pena em regime fechado.

O trabalho para o preso faz parte das diretrizes gerais da Lei de Execuções Penais - LEP, instituída pela Lei n. 7.210, de 11 de julho de 1984, não como punição, mas sim como processo de reeducação, geração de renda e produção. Além disso, a cada três dias trabalhados, o preso obtém a remição de um dia de pena. Seguem transcritos abaixo os artigos da LEP que versam sobre o assunto:

Art. 28. O trabalho do condenado, como dever social e condição de dignidade humana, terá finalidade educativa e produtiva. Art. 29. O trabalho do preso será remunerado, mediante prévia tabela, não podendo ser inferior a 3/4 (três quartos) do salário mínimo. [...] Art. 126. O condenado que cumpre a pena em regime fechado ou semiaberto poderá remir, pelo trabalho, parte do tempo de execução da pena. $\S 1^{\circ}$. A contagem do tempo, para o fim deste artigo, será feita à razão de 1 (um) dia de pena por 3 (três) de trabalho.
Sendo assim, sem que se desvirtue o propósito punitivo da condenação criminal, o que a legislação atual busca é a viabilização de um processo de regeneração do apenado, dando-lhe a perspectiva da formação profissional para que, no futuro, quando do retorno à sociedade, propicie-Ihe trabalhar em empresas ou criar seu próprio negócio. Então, suscitouse a seguinte questão: qual a visão dos sujeitos envolvidos, direta e indiretamente, sobre as atividades de trabalho remuneradas desenvolvidas por detentos na PEM - Penitenciária Estadual de Maringá? Ou seja, a intenção é compreender a visão sobre o trabalho remunerado exercido na PEM, tanto dos presos como da direção da penitenciária e também dos funcionários (técnicos e agentes prisionais).

\section{OS SENTIDOS DO TRABALHO}

Ao longo da História, o trabalho e as pessoas sofreram importantes transformações, mas, no entanto, continua sendo o trabalho um ícone de expressão na sociedade em que se vive pela contribuição que vem prestando na evolução, cultura e formação de identidade do ser humano, pois o trabalho e os resultados que são alcançados ajudam o indivíduo nessa direção. Para Antunes (2004: 13), o papel do trabalho vai mais além, quando disse que:

O trabalho é a fonte de toda a riqueza, afirmam os economistas. Assim é, com efeito, ao lado da natureza, encarregada de fornecer os materiais que ele converte em riqueza. O trabalho, porém, é muitíssimo mais do que isso. É a condição básica e fundamental de toda a vida humana. E em tal grau que, até certo ponto, podemos afirmar que o trabalho criou o próprio homem.

A natureza do trabalho, nos tempos atuais, tem mostrado seu papel na vida do homem, esboçando, entretanto, um panorama confuso para o futuro, pois os conceitos de trabalho de outrora enfatizavam sua principal destinação à simples produção de bens e serviços, em que a exigência por produtividade (o que tem gerado o desemprego ou subemprego) e a introdução de tecnologia ainda não eram fontes de preocupação. Harman \& Hormann (1997) afirmaram que o significado do trabalho, na sociedade moderna, está envolto em um turbilhão de outras demandas que superam, em muito, apenas as questões do desemprego ou subemprego, em busca de um trabalho significativo e satisfatório: 
Um trabalho significativo não é necessariamente um trabalho instigante cheio de desafios a todo momento; será suficiente que faça parte de uma iniciativa maior, esta sim, repleta de significados. É principalmente essa iniciativa "maior" que falta à nossa sociedade moderna (HARMAN \& HORMANN, 1997, p. 26).

Sabe-se que a satisfação e a motivação de quem trabalha estão atreladas ao entendimento sobre o trabalho que realiza e às características que precisa ter para dar um sentido àquilo que faz. Sendo assim, o que atribui significado ao trabalho parece ser o objetivo pelo qual ele é executado, o que acaba por ser individual e específico a cada ser humano. Portanto, é preciso que se visualize que o trabalho e seus significados, ao longo da História, têm exercido papel fundamental na vida dos homens, contribuindo de forma determinante para a formação da cultura, identidade e da própria essência humana. A esse respeito, Antunes (1999), quando tratou sobre o processo de trabalho, mencionou que:

Antes de tudo, o trabalho é um processo entre o homem e a natureza, um processo em que o homem, por sua própria ação, medeia, regula e controla seu metabolismo com a natureza [...]. Ele não apenas efetua uma transformação da forma da matéria natural; realiza, ao mesmo tempo, na matéria natural seu objetivo, que ele sabe que determina, como lei, a espécie e o modo de sua atividade e ao qual tem de subordinar sua vontade (ANTUNES, 1999: 36-37).

O trabalho, assim, deve preencher algumas lacunas, deve enaltecer a razão pela qual o executamos, de forma a refletir o que somos e como somos vistos no mundo. Portanto, o trabalho acaba por ter um valor intrínseco e é necessário que seu resultado seja um produto útil, prático e que proporcione ao homem o sentimento de autorrespeito, dignidade, e não algo que signifique apenas a sobrevivência. Sobre o trabaIho como atividade humana, Codo \& Sorato (1999: 111) respaldaram essa ideia, quando mencionaram:

Estamos falando do trabalho visto não como mera necessidade para a sobrevivência, concreto, objetivo, inserido no mercado de trabalho formal ou informal, mas sim como uma atividade humana nobre e muito especial. E o que tem de especial nesta atividade, o que a diferencia de outras tantas atividades que realizamos no nosso contato cotidiano com o mundo que habitamos? É simples: falamos em trabalho quando, independente da relação financeira definida por vínculos empregatícios, contratos de trabalho, salários, deveres e direitos trabalhistas, uma atividade que resulta em um produto que transforma a natureza e permanece no tempo e no espaço.

Não é incomum que a maioria dos trabalhadores de hoje não consiga dar sentido ao seu trabalho, porém isso não quer dizer que o trabalho, para simples sobrevivência, baste. O espaço que o trabalho ocupa na vida do ser humano produtivo é exponencialmente maior que o da subsistência simplesmente; ele é a perpetuação do homem na humanidade. E assim mencionou Antunes (2004: 8), a partir dos escritos de Marx:

O trabalho é também fundamental na vida humana porque é condição para sua existência social. Conforme disse Marx em O capital: "Como criador de valores de uso, como trabalho útil, é o trabalho, por isso, uma condição de existência do homem, independentemente de todas as formas de sociedade, eterna necessidade natural de mediação do metabolismo entre o homem e natureza e, portanto, vida humana".

Sendo assim, dar sentido ao trabalho, dar importância àquilo que faz, torna o indivíduo cônscio de sua importância e da importância social do trabalho e isso representa algo muito maior que, inclusive, transpõe a sua própria existência. Pois foi nesse sentido que Codo \& Vasques-Menezes (1999: 293) enfatizaram a importância social do trabalho:

Um trabalhador que apresenta problemas quanto à percepção do produto de seu trabalho é um indivíduo que não vê importância naquilo que faz, não enxerga que seu trabalho tem valor [...]. A importância da percepção do próprio trabalho como útil à sociedade tem valor inegável para a autoestima do trabalhador, para forma como se estrutura sua identidade; sentir que realizamos um trabalho inútil faz de alguma maneira, com que nos sintamos também inúteis.

Tudo isso remete aos escritos da filósofa alemã Hannah Arendt, mais especificamente em relação à 
sua obra denominada $A$ condição humana, publicada em 1958, quando discutiu, em seus capítulos centrais, sobre o labor, o trabalho e a ação, que serviu de base na análise dos dados coletados, apresentada a posteriori neste artigo.

\section{LABOR, TRABALHO E AÇÃO}

Para Arendt (2004), o viver do homem na Terra está atrelado, mais especificamente, a três atividades fundamentais que, conjuntamente, dão sentido ao que ela denominou de vita activa. São elas: o labor, o trabalho e a ação. Portanto, as expressões condição humana e vita activa estão diretamente vinculadas à afirmação do homem como ser vivo, conquistando seu espaço no mundo em que vive e atua:

A condição humana compreende algo mais que as condições nas quais a vida foi dada ao homem. Os homens são seres condicionados: tudo aquilo com o qual eles entram em contato torna-se imediatamente uma condição de sua existência. O mundo no qual transcorre a vita activa consiste em coisas produzidas pelas atividades humanas; mas, constantemente, as coisas que devem sua existência exclusivamente aos homens também condicionam seus autores humanos. Além das condições nas quais a vida é dada ao homem na Terra e, até certo ponto, a partir delas, os homens constantemente criam suas próprias condições que, a despeito de sua variabilidade e sua origem humana, possuem a mesma força condicionante das coisas naturais. O que quer que toque a vida humana ou entre em duradoura relação com ela, assume imediatamente o caráter de condição da existência humana (ARENDT, 2004: 17).

Iniciando pelo "labor", Arendt (2004) atribuiu a essa atividade a própria sobrevivência do ser humano, em busca da satisfação de suas necessidades básicas. Assim, por exemplo, o alimento produzido pelo homem para ser consumido por si ou por sua família, a fim de que consiga somente dar manutenção à vida. Portanto, a condição humana do labor é a vida, o empenho do homem na luta pela sobrevivência.

Foi nessa perspectiva que Arendt (2004) considerou o homem como "animal laborans" e que não consegue dele se desvincular, pois o labor é fruto de uma necessidade biofisiológica, inacabável, ou seja, semelhante aos ciclos biológicos dos organismos vivos, que só se encerram com a morte de tal organismo. Portanto, Arendt (2004) reduziu o labor a uma atividade vã que nada produz de durável e que sacrifica o homem a uma vida sem expressão e limitada, buscando apenas a perpetuação da espécie:

[...] o animal laborans não foge do mundo, mas dele é expelido na medida em que é prisioneiro da privatividade do próprio corpo, adstrito à satisfação de necessidades das quais ninguém pode compartilhar e que ninguém pode comunicar inteiramente (ARENDT, 2004: 131).

No entanto, como "trabalho" Arendt (2004) entendeu a atividade executada pelo homem, que nesse momento tem o domínio sobre a natureza, passando da condição de animal laborans para Homo faber, ou seja, aquele que, por meio do trabalho, cujo resultado é objetivo e pode ser mensurado - um produto, um bem de consumo qualquer -, coloca-se um passo adiante do animal laborans, e como criativo e fabricante de coisas, objetos que possuem valor de uso ou de troca que, com isso, credenciam-no a permanecer no mundo, não como servo da natureza, e sim, como senhor soberano da terra (ARENDT, 2004). Seguindo o mesmo raciocínio, Lafer (2004: 345) reforçou o conceito de trabalho, afirmando que:

O trabalho, ao contrário do labor, não está necessariamente contido no repetitivo ciclo vital da espécie. É através do trabalho que o Homo faber cria coisas extraídas da natureza, convertendo o mundo num espaço de objetos partiIhados pelo homem. O hábitat do humano é, por isso mesmo, nitidamente diferente de qualquer ambiente natural. E um hábitat cercado de objetos que se interpõem entre a natureza e o ser humano, unindo e separando os homens entre si.

Percebe-se, então, que o limite foi ultrapassado, quando o Homo faber interfere e atua sobre a natureza, fabricando objetos com a prerrogativa de criá-los e, ao mesmo tempo, destruí-los, com a segurança de que nenhum desses produtos é tão vital à sua sobrevivência que não possa, à sua vontade, mantê-los ou deles prescindir. "O Homo faber é realmente amo e senhor, não apenas porque é o senhor ou se arrogou o papel de senhor de toda a natureza, mas porque é senhor de si mesmo e de seus atos" (ARENDT, 2004: 157). 
Este comportamento fabril, que degrada o mundo e subverte o valor das coisas em si em valor-utilidade, passa a ser meio para se alcançar outras coisas. Esta é a característica do Homo faber. Os bens, de forma geral, passam a ser fins em si mesmos, não se integrando novamente ao homem ou à sociedade. Dividem o mundo com o próprio homem e possuem características de multiplicação, ou seja, características estas inerentes ao trabalho e que não podem ser confundidas com a repetição, que é fruto do labor. O processo que envolve a busca de solidez e valoração dos bens produzidos é denominado por Arendt (2004) como reificação. A referida autora ainda asseverou que:

[...] a exultação sentida no exercício violento de uma força com a qual o homem se mede contra as forças devastadoras da natureza e que, através da astúcia com que inventou as ferramentas, sabe multiplicar muito além de sua medida natural. A solidez resulta dessa força, e não do prazer ou da exaustão que o homem sente quando provê o próprio sustento <com o suor de seu rosto>; e não é simplesmente tomada de empréstimo ou colhida como dádiva gratuita da natureza eternamente presente, embora fosse impossível sem o material arrancado da natureza. A solidez já é um produto do homem (ARENDT, 2004: 153).

Essa transição entre o animal laborans e o Homo faber fica evidenciada com o uso da técnica na natureza, para sua formação utilitária, ou seja, para a produção de bens que sejam meios e fins.

Como terceira atividade fundamental da vita activa, tem-se a "ação", que, por sua vez, só pode ser exercitada com outros homens. A convivência é condição indispensável para o exercício da ação, impossível de ocorrer no isolamento. Essa é a condição humana da pluralidade (igualdade e diferença), que torna os homens singulares, através do discurso de que a ação é revelada, fazendo com que o homem se exponha e participe do mundo. Portanto, a pluralidade humana é responsável pela compreensão entre os homens e com palavras e atos, e que estes se transportam para o mundo humano:

A pluralidade humana, condição básica da ação e do discurso, tem duplo aspecto: de igualdade e diferença. Se não fossem iguais, os homens seriam incapazes de compreenderem-se (sic) entre si e aos seus ancestrais, ou de fazer planos para o futuro e prever as necessidades das gerações vindouras. Se não fossem diferentes, se cada ser humano não diferisse de todos que existiram, existem ou virão a existir, os homens não precisariam do discurso ou da ação para se fazerem entender (ARENDT, 2004: 188).

Assim, a ação e o discurso propiciam as relações humanas, semelhantes à Polis grega, onde os homens se desatrelavam de suas necessidades naturais ou animais para um agir livre que remetia o homem (autogovernado) a uma esfera política, que o integrava e the dava capacidade de agir e de falar. Este é o Homo sapiens, que transpõe sua condição de trabalhador para a de cidadão, que convive em um espaço plural e marca sua passagem, não pela presença física, mas pelo seu modo de ser e agir. Em relação a isso, Lafer (2004: 345) asseverou que "[...] a ação na obra de Hannah Arendt, é uma das categorias fundamentais e representa não só um médium da liberdade, enquanto capacidade de reger o próprio destino, como também a forma única da expressão de singularidade individual".

O que Arendt (2004) procurou mostrar foram as várias manifestações humanas, mediante o trabalho, figuradas a partir do animal laborans, que prioriza a sobrevivência de si e de seus familiares, buscando a manutenção sistemática das necessidades biofisiológicas; do Homo faber, empenhado na construção do mundo, marcando sua passagem como indivíduo, interferindo e atuando sobre a natureza; e o Homo sapiens, que é a própria ação ou construção da existência, o crescimento intelectual, a busca de si. Portanto, o espaço e o tempo que foram concedidos ao homem na Terra deram-lhe a incumbência de sobreviver, de construir o mundo e de existir (ARENDT, 2004).

Os conceitos sobre o trabalho estão impregnados com uma significativa dose de identidade com sua função social primária, qual seja a de produzir o necessário e garantir a continuidade da vida. Asseverou Gorz (1982) que a forma de trabalho conhecida como emprego é fruto do capitalismo industrial, mais especificamente um conceito contemporâneo advindo da indústria. O autor em tela enfatizou a importância de se diferenciar conceitualmente o entendimento de emprego e de trabalho. O que está em 
crise, portanto, é a forma de trabalho entendida como emprego, pois o trabalho em si é algo que traz em sua essência uma riqueza e amplitude que extrapola o significado do emprego. Portanto, o trabalho vem adquirindo, ao longo dos anos, a característica de fator importante que impulsiona a economia e a sociedade, à medida que gera renda e permite que os indivíduos sobrevivam (trabalho remunerado), mantendo assim uma relação social fundamental.

No entanto, o trabalho como é conhecido, que se pratica e se posiciona no centro da vida individual e social, é fruto da modernidade advinda do industrialismo. Para os gregos, o labor representava a luta pela sobrevivência física, ou seja, realizado para a manutenção da vida e da sobrevivência da espécie humana. Havia, então, uma relação direta entre produção e consumo, ou seja, tudo o que resultava do labor era imediatamente consumido. Em relação à hierarquia de valores dos ideais gregos, era uma atividade pouco valorizada e a menos importante na vita activa (Gorz, 1980).

O trabalho era visto como atividade que exaltava e produzia um mundo de artificialidades. Segundo Arendt (2004), a condição humana do trabalho é a mundanidade. Essa atividade não mais necessita do organismo humano, por inteiro, e o homem passa a ser dependente de suas mãos, ferramenta essencial que o transportou da condição de animal laborans para o Homo faber, aquele que fabrica, que obra.

A ação, terceira atividade fundamental da vita activa, caracteriza-se como condição humana da pluralidade, pois é exercitada entre os homens, sem a necessidade de qualquer outro tipo de matéria. Portanto, suas principais características ficam por conta da pluralidade, da ausência de interferência de coisas ou materiais, do seu exercício na esfera pública, da intransferibilidade, pois nenhum ser humano pode abdicar do discurso e da ação, sem o qual a vida humana sucumbiria. O produto da ação são reflexões, ensinamentos e relações que representam atividade exercida exclusivamente pelo homem.

Essa, portanto, foi a perspectiva sob a qual os gregos estabeleceram a hierarquia dos componentes da vita activa, onde a ação galgava o mais alto conceito, e isso contribuiu sobremaneira para clarificar as mudanças que ocorreram, em termos de valores, a visão de mundo e suas atividades humanas a partir do surgimento da sociedade industrial. Uma das principais evidências dessa mudança de valores está no conceito que os gregos tinham do trabalho, atividade que era atribuída ao ser humano como castigo, nocivo à sua imagem e, sobretudo, distante da condição de estabelecer laços sociais entre as pessoas.

Com isso, é oportuno enfatizar o que Gorz (1982) disse sobre o trabalho e suas atuais peculiaridades, passando a ser uma atividade realizada na esfera pública, onde todos possam ver distintamente do que ocorria no mundo antigo. O trabalho hoje, reconhecido como importante e útil, configura-se como um esforço remunerado despendido pelo homem; importante elemento de existência e conquista de identidade social; e, na atualidade, fator de exclusão social, pois o trabalho ainda não conseguiu se desatrelar da realidade que o envolve, fazendo com que ele se realize em condições e relações de poder ainda bastante desiguais.

Por que trabalhar? Trabalhar é uma necessidade? Ou é apenas um meio de ganhar a vida? Ou a única maneira - por mais imperfeita que seja, na maior parte das vezes - de se inserir na sociedade, de estar em relação com os outros, de escapar ao isolamento e ao sentimento de inutilidade? Ou tudo isso ao mesmo tempo? (GoRz, 1982: 173).

\section{O SENTIDO DO TRABALHO PARA OS PRESOS}

O sentido do trabalho, para aquele que está segregado do convívio social, apresenta perspectiva um pouco diferente em relação ao trabalhador livre. No entanto, é fato que o trabalho possui uma importância bastante significativa na dinâmica de funcionamento da sociedade atual; portanto, inserir o preso nesse contexto e dar-lhe as mínimas condições para que possa sobreviver e retomar sua vida, dentro de uma condição favorável à superação dos efeitos da exclusão social, bem como das tentações de retorno à criminalidade, é um objetivo a ser alcançado.

O trabalho bem dimensionado, para o preso, é dignificante, apoia sua família e o municia das condições necessárias ao retorno à sociedade para uma nova vida. Encontrar o dimensionamento ideal, em busca de tal objetivo, não é tarefa fácil. Em relação a isso, Pastore (2001), quando falou sobre trabalho 
prisional, demonstrou preocupação com respeito à complexidade e aos custos dessa proposta. Todavia, tal autor entendeu ser necessária essa busca, a fim de que se evitem maiores tensões nas cadeias e um colapso social, quando do retorno desses indivíduos para a sociedade:

É falsa a ideia comum de que, ao submeter os presos a qualquer tipo de trabalho - em especial os duros e pesados - isso atuará como um castigo para ensinar uma lição e evitar a reincidência no crime. Isso não quer dizer que o trabalho prisional não deve ser realizado. Significa apenas que as soluções simplistas de impor ao preso um trabalho que ele não quer fazer, além de ilegal, não ajudam em nada na reorganização de sua vida depois da pena cumprida (PASTORE, 2001: 2).

Apesar da complexidade desse processo, apontada por Pastore (2001), Coutinho (1999) defendeu a necessidade da realização do trabalho pelos apenados, para a superação dos problemas advindos da exclusão social. Nesse sentido, o autor em referência disse o seguinte:

Constitui o trabalho um direito e um dever social dos apenados, reeducativo e produtivo, de forma a possibilitar o alcance dos escopos secundários a que se destina a pena, e não uma obrigação imputada por sentença. Outrossim, diz-se, poderá preparar-se o preso com formação profissional para o mercado de trabalho que deverá enfrentar o futuro, quando recuperar sua liberdade, pelo cumprimento da pena [...] (Coutinho, 1999: 7).

Quando Dupas (1999) estudou sobre o trabalho e a exclusão social, concluiu que o desemprego é um dos principais determinantes da exclusão social, potencializando, sobremaneira, a incidência do crime e que o sentimento de desamparo, proveniente da própria exclusão social, dentre outros aspectos, é das principais causas da criminalidade e pode ser minimizada com o trabalho. Além disso, sem estarem tratando especificamente sobre o trabalho prisional, Codo \& Sorato (1999) asseveraram que:

O trabalho, enquanto atividade criativa e de transformação, modifica não apenas o mundo, mas também o homem que o executa. 0 homem se reconhece no seu trabalho e se orgulha daquilo que constrói, se orgulha do fruto do seu trabalho e também se transforma nesse processo. Modifica seus hábitos, seus gostos, seu jeito de se vestir, seu modo de comportar-se. O trabalho enriquece o homem, e não estamos aqui falando em dinheiro, em acúmulo de bens, estamos falando em conhecimento, experiência, habilidades, enfim, desenvolvimento da forma mais ampla que podemos pensar (Codo \& SORATO, 1999: 112).

Ressalta-se que, apesar de o Brasil ainda não possuir uma política bem estruturada e clara sobre o trabalho prisional, o País tem sinalizado, mediante projetos e discussões, propostas voltadas a modificações, na Lei de Execuções Penais - LEP, para que o trabalho do preso tenha finalidade produtiva e educativa e, além disso, seja remunerado e em coadunação com a vontade e a aptidão do preso. Sobre a percepção desse fato na Penitenciária Estadual de Maringá é o que a presente pesquisa se propôs investigar.

\section{PROCEDIMENTOS METODOLÓGICOS}

O lócus da pesquisa foi a Penitenciária Estadual de Maringá - PEM, inaugurada em 10 de abril de 1996. Os canteiros de trabalho existentes na PEM são aqueles oferecidos pela própria unidade, e que são denominados de canteiros internos, bem como outros que existem mediante convênios entre a Secretaria de Estado da Justiça e Cidadania e organizações que utilizam mão de obra prisional.

A atividade nos canteiros propicia ao preso a remição da pena, pois, a cada três dias trabalhados, reduz-se um dia da pena a ser cumprida. Em contrapartida, as empresas conveniadas são beneficiadas com a isenção de encargos sociais referentes às questões trabalhistas que incidem sobre o trabalhador. Quando da realização da pesquisa no segundo semestre de 2006, a PEM possuía 360 pessoas cumprindo pena e, destas, 180 desenvolviam atividades de trabalho remuneradas em canteiros de trabalho nela instalados.

A pesquisa realizada possui abordagem interpretativa, tipo descritivo, natureza qualitativa, com corte transversal, sendo que, para tanto, foram realizadas entrevistas semiestruturadas, transcritas e gravadas, com a autorização dos sujeitos envolvidos. Para a 
amostra, foram, em princípio, selecionados de forma intencional canteiros de trabalho de acordo com a facilidade de acesso dos pesquisadores. Posteriormente, foram escolhidos, de forma aleatória, 16 presos que exerciam atividades de trabalho remuneradas na PEM; oito agentes penitenciários; cinco técnicos, sendo eles dois psicólogos, dois assistentes sociais e um pedagogo; e o diretor da unidade, perfazendo um total de 30 entrevistas. Ressalta-se ainda que foi realizado, antes desse processo todo, um teste-piloto, para verificar se o roteiro de entrevistas necessitava de algum ajuste.

\section{APRESENTAÇÃO E INTERPRETAÇÃO DOS DADOS}

A partir desse momento, apresentar-se-ão as múltiplas visões a respeito do trabalho remunerado exercido na PEM, a partir da interpretação da narrativa dos sujeitos envolvidos direta ou indiretamente com essa atividade.

\section{a) Presos}

As respostas obtidas quando os presos foram indagados sobre o que significava o trabalho para eles estão sintetizadas no Quadro 1, apresentado.

Ao se interpretarem as falas dos presos, percebese a relevância do trabalho em suas vidas, e que as atividades de trabalho por eles desenvolvidas não significam castigo, mas algo benéfico, ou seja, uma maneira de se sentirem parte de um grupo de pessoas que produzem algo útil. Isso vem ao encontro da posição de Codo \& Vasques-Menezes (1999: 293), pois, para eles, "[...] a importância da percepção do próprio trabalho como útil à sociedade tem valor inegável para a autoestima do trabalhador, para a forma como se estrutura sua identidade [...]".

Os presos se manifestaram em relação à busca pela satisfação de necessidades de ordem biológica, subsistência de si próprio e de seus familiares, o que se coaduna com o conceito de labor, pois "o animal laborans não foge do mundo, mas dele é expelido na medida em que é prisioneiro da privatividade do próprio corpo, adstrito à satisfação de necessidades das quais ninguém pode compartilhar [...]" (ARENDT, 2004: 131).

Outro aspecto referente ao labor se manifesta nos depoimentos dos presos quando estes citam a
Quadro 1: Sinopse das entrevistas realizadas com os presos da PEM

\begin{tabular}{|l|l|}
\hline Categorias estudadas & Visões que emergiram \\
\hline trabalho executado pelo preso & $\begin{array}{l}\text { Devolução da cidadania } \\
\text { Aprendizagem de um ofício } \\
\text { Perspectiva de um futuro melhor } \\
\text { Terapia ocupacional } \\
\text { Valorização pessoal } \\
\text { Melhora na qualidade de vida } \\
\text { Redução da pena } \\
\text { Perspectiva de mudar de vida } \\
\text { Aprendizagem de valorização } \\
\text { do dinheiro }\end{array}$ \\
\hline Sobre a remuneração recebida & $\begin{array}{l}\text { Ajuda financeira à família } \\
\text { Possibilidade de adquirir alimentos } \\
\text { diferentes e materiais de higiene } \\
\text { pessoal } \\
\text { Contribuição financeira com a família }\end{array}$ \\
\hline Sobre trabalhar sem obter remição & $\begin{array}{l}\text { Exercício de uma atividade de } \\
\text { trabalho quando sair da prisão }\end{array}$ \\
\hline de pena & $\begin{array}{l}\text { Dificultação da permanência na } \\
\text { prisão } \\
\text { Aumento dos conflitos com os } \\
\text { constatação de que os presos } \\
\text { companheiros } \\
\text { Aperfeiçoamento do sujeito na vida } \\
\text { criminosa, pois "mente vazia é } \\
\text { oficina do diabo" }\end{array}$ \\
\hline de trabalho de exercer uma atividade \\
\hline
\end{tabular}

Fonte: entrevistas.

importância do trabalho como terapia ocupacional, pois "o labor é a atividade na qual o corpo se desgasta com a finalidade de atender às necessidades da vida" (ARENDT, 2004: 94). Para os presos, trabalhar é um meio de gastar energia acumulada, exaurir-se e preencher o tempo ocioso.

No entanto, apesar das características simples das atividades de trabalho que exercem, os presos também se preocupam com o dinheiro que ganham nas atividades de trabalho, com a possibilidade de obter formação profissional, para que, no futuro, possam se reintegrar à sociedade.

Isso Ihes imputa também a condição de Homo faber, ou seja, aquele que, por meio do trabalho, cujo resultado é objetivo e pode ser mensurado - um produto, um bem de consumo qualquer - coloca-se um passo adiante do animal laborans, e como criativo 
e fabricante de coisas, objetos que possuem valor de uso ou de troca que, com isso, credenciam-no a permanecer no mundo, não como servo da natureza e, sim, como senhor soberano da terra (ARENDT, 2004). Ou seja, apesar de prioritariamente o trabalho, para eles, significar a satisfação de necessidades de manutenção, significa também a possibilidade de troca e a criação de condições para um futuro melhor.

\section{b) Agentes penitenciários}

A interpretação das falas dos agentes penitenciários sobre o que eles pensam a respeito das atividades de trabalho remuneradas, desenvolvidas pelos presos, encontra-se sintetizada no Quadro 2, apresentado abaixo.

Ao se avaliarem as declarações dos agentes sobre o significado do trabalho exercido pelos presos, percebeu-se como posicionamentos predominantes

Quadro 2: Sinopse das entrevistas realizadas com os agentes penitenciários da PEM

\begin{tabular}{|l|l|}
\hline Categorias estudadas & Visões que emergiram \\
\hline executado pelo preso & Aprendizagem de um ofício \\
& Perspectiva de um futuro melhor \\
& Terapia ocupacional \\
& Remição de pena \\
& Redução de conflitos \\
& Recuperação do preso \\
& Manutenção da dignidade do apenado \\
\hline Sobre se conceder trabalho & Visão do trabalho para os presos \\
para o preso & com ressalvas \\
& Consciência de que é importante, desde \\
& que não interfira na segurança \\
& Concepção de que o trabalho é \\
& secundário \\
& Facilitação do trabalho do agente \\
& Existência de outros fatores mais \\
& importantes do que o trabalho, tais como \\
& a educação e o lazerldeia de ser uma \\
& obrigação \\
& Presença de pressão psicológica \\
& Valorização do material de uso pessoal \\
& Dificultação do controle, devido ao uso de \\
ferramentas & Auxílio à família \\
& Extrapolação das funções do agente \\
& Convicção de ser uma atividade essencial \\
& Redução de tensões \\
& Ocupação do tempo ocioso \\
& Exigência maior do funcionário (agente \\
& penitenciário) \\
\hline
\end{tabular}

Fonte: entrevistas. duas questões principais, quais sejam: a primeira corresponde à necessidade do trabalho como elemento regulador de tensões dentro da prisão, e a segunda, como forma de auxílio financeiro e remição da pena. No entanto, eles mostram preocupação com a segurança dentro da PEM, ou seja, com o uso de ferramentas e utensílios, que podem ser mal utilizados por quem assim o quiser. Essa realidade pode tornar frágil a figura do agente penitenciário também como educador nesse processo, em razão de sua preocupação maior (válida, é bom que se ressalte) com a segurança no presídio.

\section{c) Técnicos}

As falas dos técnicos, quais sejam psicólogos, assistentes sociais e pedagogo, sobre a visão deles em relação às atividades de trabalho remuneradas desenvolvidas pelos presos foram sintetizadas, conforme demonstra o Quadro 3, apresentado.

Pode-se observar, na fala dos técnicos, ou seja, dos psicólogos, assistentes sociais e pedagogo, que estes consideram as atividades de trabalho remuneradas de fundamental importância para o preso. 0 que se notou, na fala deles, e talvez pelas condições físicas e humanas do lócus da pesquisa, a visão do trabalho ainda predominantemente como labor. No entanto, eles não descartaram o fato de o preso sonhar com a possibilidade de transcender efetivamente para uma condição de Homo faber. Coutinho (1999) disse que o trabalho é um direito dos apenados, e não uma obrigação imputada por sentença, e que se pode prepará-los profissionalmente para enfrentar o futuro quando recuperarem a liberdade após o cumprimento da pena. Esta foi a visão predominante desses sujeitos entrevistados.

\section{d) Diretor}

No Quadro 4, está sintetizada a visão do diretor da unidade sobre as atividades de trabalho remuneradas, exercidas pelos detentos da PEM. Sua visão não se distancia daquelas apresentadas pelos outros entrevistados, principalmente os técnicos. Ou seja, apesar de ver o trabalho dos presos como labor, também se preocupa com a necessidade de propiciar a possibilidade de o preso transcender efetivamente da condição de animal laborans para Homo faber. 
Quadro 3: Sinopse das entrevistas realizadas com os técnicos da PEM

\begin{tabular}{|c|c|}
\hline Categorias estudadas & Visões que emergiram \\
\hline \multicolumn{2}{|l|}{ Psicólogas } \\
\hline $\begin{array}{l}\text { Sobre o significado do } \\
\text { trabalho executado pelo preso }\end{array}$ & $\begin{array}{l}\text { Reconhecimento social } \\
\text { Ressocialização } \\
\text { Aprendizagem de um ofício } \\
\text { Valorização da pessoa Integração }\end{array}$ \\
\hline $\begin{array}{l}\text { Sobre se conceder trabalho } \\
\text { para o preso }\end{array}$ & $\begin{array}{l}\text { Condição de que leva à inclusão social } \\
\text { Função socialSentimento de utilidade } \\
\text { Terapia ocupacional } \\
\text { Ajuda ao trabalho técnico }\end{array}$ \\
\hline \multicolumn{2}{|l|}{ Assistentes sociais } \\
\hline $\begin{array}{l}\text { Sobre o significado do } \\
\text { trabalho executado pelo preso }\end{array}$ & $\begin{array}{l}\text { Crescimento pessoal } \\
\text { Remição de pena } \\
\text { Formação para o ingresso } \\
\text { no mercado de trabalho } \\
\text { Disciplina } \\
\text { Terapia ocupacional } \\
\text { Aprendizagem da convivência em grupo, } \\
\text { da participação e da assunção de } \\
\text { responsabilidade }\end{array}$ \\
\hline $\begin{array}{l}\text { Sobre se conceder trabalho } \\
\text { para o preso }\end{array}$ & $\begin{array}{l}\text { Melhora da autoestima } \\
\text { Existência da necessidade de conceder } \\
\text { trabalho a todos os presos, aumentar o } \\
\text { tempo de trabalho e enriquecer as funções } \\
\text { Contribuição com a manutenção do preso } \\
\text { Contribuição financeira à família }\end{array}$ \\
\hline \multicolumn{2}{|l|}{ Pedagoga } \\
\hline $\begin{array}{l}\text { Sobre o significado do } \\
\text { trabalho executado pelo preso }\end{array}$ & $\begin{array}{l}\text { Aprendizagem para se disciplinar e cumprir } \\
\text { normas } \\
\text { Ressocialização } \\
\text { Profissionalização } \\
\text { Possibilidade de um futuro melhor } \\
\text { Manutenção da dignidade do preso }\end{array}$ \\
\hline $\begin{array}{l}\text { Sobre se conceder trabalho } \\
\text { para o preso }\end{array}$ & Contribuiç̧ão financeira à família \\
\hline
\end{tabular}

Fonte: entrevistas.

Quadro 4: Sinopse da entrevista realizada com o diretor da PEM

\begin{tabular}{|l|l|}
\hline Categorias estudadas & Visões que emergiram \\
\hline $\begin{array}{l}\text { Sobre o significado do } \\
\text { trabalho executado pelo preso }\end{array}$ & $\begin{array}{l}\text { Terapia ocupacional } \\
\text { Ressocialização } \\
\text { Reintegração social } \\
\text { Profissionalização }\end{array}$ \\
\hline $\begin{array}{l}\text { Sobre se conceder trabalho } \\
\text { para o preso }\end{array}$ & $\begin{array}{l}\text { Contribuição financeira à família } \\
\text { Redução de conflitos }\end{array}$ \\
\hline
\end{tabular}

Fonte: Entrevista.

\section{CONCLUSÕES}

Muito embora os sujeitos envolvidos nesta pesquisa estejam alocados em posições diferentes e busquem alcançar objetivos igualmente diferentes, todos, indistintamente, fazem parte da tessitura que envolve as atividades de trabalho remunerado na PEM. Os presos estão envolvidos diretamente no trabalho executado nos canteiros instalados; os demais, ou seja, agentes penitenciários, psicólogos, assistentes sociais, pedagogo e diretor da unidade estão envolvidos indiretamente, pois, embora percebam uma remuneração, esta não advém das atividades desenvolvidas nos canteiros de trabalho instalados na penitenciária.

Em relação às visões dos sujeitos envolvidos de forma direta e indireta nas atividades de trabalho remunerado na PEM, conclui-se que o trabalho para o preso não representa o cumprimento de pena ou castigo, mas um fator estruturador que lhe permite crescimento pessoal, por meio do desenvolvimento profissional e intelectual, o que significa a esperança de conseguir reconstruir a vida na ocasião de sua volta ao convívio social, o resgate da confiança em si mesmo, a melhora de sua imagem diante dos familiares, de si mesmo e, consequentemente, o resgate da autoestima. Com a remuneração percebida, o detento adquire materiais de primeira necessidade, o que faz com que ele se sinta bem consigo e, por vezes, tenha condições de ajudar sua família em pequenas despesas. Isso caracteriza a atividade investigada como labor, que, segundo Arendt (2004), são atividades humanas fundamentais exercidas pelo denominado animal laborans, as quais priorizam a sobrevivência de si e de seus familiares.

A visão dos agentes penitenciários em relação às atividades de trabalho remuneradas difere um pouco da dos presos. Para eles, o exercício das referidas atividades possui caráter paradoxal, pois, ao mesmo tempo que facilita o exercício de sua função pelo fato de que, quando os internos exercem uma atividade de trabalho, costumam apresentar um comportamento tranquilo, por outro, o exercício do trabalho dentro da penitenciária causa apreensão, devido ao uso de certas ferramentas de trabalho utilizadas nos canteiros que, por vezes, representam perigo, causando tensão entre os agentes. 
Para os psicólogos, as atividades de trabalho remuneradas desenvolvidas pelos presos na PEM significam a mediação entre eles e a sociedade, pois contribuem para o processo de ressocialização e inclusão social, melhoram o convívio do grupo de prisioneiros, fazem com que estes se sintam valorizados, preenchendo necessidades psicológicas e fisiológicas, melhorando a autoestima; exercem também o papel de um moderador de tensões. Para as assistentes sociais, significam uma forma de preencher necessidades e auxiliar os familiares, além de se tornarem um vetor moderador de tensões. Para o pedagogo, significam a possibilidade de auxiliar a família, preencher necessidades fisiológicas, promover inclusão social e ressocialização.

Quanto à visão do diretor da PEM em relação às atividades de trabalho remuneradas desenvolvidas pelos presos, elas significam, além da possibilidade de o detento auxiliar no sustento de sua própria família, um caminho para sua formação profissional e ressocialização, culminando com aspectos observados na visão dos demais envolvidos nas atividades de trabalho remuneradas desenvolvidas pelos detentos. Conclui-se, então, que a visão do diretor da PEM não difere substancialmente da visão dos demais técnicos entrevistados.

Assim, as atividades de trabalho desenvolvidas pelos detentos da PEM possuem características semelhantes às daquelas denominadas por Hannah Arendt (2004) de labor, pois os benefícios deste trabalho são revertidos para o próprio sustento dos presos, mantendo então o ciclo vital e continuidade da vida. Notou-se também que o trabalho para o preso na PEM possui, em alguns momentos, significado semelhante à de outros grupos de trabalhadores, mesmo sendo desenvolvido em uma penitenciária e com características bem peculiares. Ou seja, para os sujeitos envolvidos na pesquisa, aqueles que desenvolvem atividades de trabalho remunerado na PEM, estão em determinados momentos na condição de animal laborans, mas, em outros, estão também na condição de Homo faber, salvo as devidas adequações, no tempo e no espaço.

Conclui-se, então, que o trabalho, independentemente de possuir características de labor desenvolvido pelo animal laborans ou de trabalho desenvolvido pelo Homo faber, bem como na condição de Homo sapiens, ou seja, aquele que se empenha na construção do mundo, interferindo e atuando sobre a natureza, é um fator estruturante e formador de identidade para o homem, principalmente desse indivíduo que se encontra preso, como é o caso ora em estudo.

Por fim, ressalta-se que os resultados aqui apresentados poderiam ser enriquecidos com outras informações advindas de pesquisas que versassem sobre a situação dos egressos, hoje, para averiguar se as atividades de trabalho desenvolvidas pelos presos na PEM ressocializam, de fato, e de que forma isto ocorre, bem como outros aspectos de cunho psicossocial, inerentes às peculiaridades desses indivíduos.

Salienta-se, ainda, que não foram encontrados estudos sobre atividades de trabalho desenvolvidas por detentos, o que certamente poderia ter enriquecido este artigo. 


\section{REFERÊNCIAS}

Antunes, Ricardo. Adeus ao trabalho: ensaio sobre as metamorfoses e a centralidade do mundo do trabalho. São Paulo: Cortez, 1999.

- A dialética do trabalho. São Paulo: Expressão Popular, 2004.

ArendT, Hannah. A condição humana. 10. ed. Rio de Janeiro: Forense Universitária, 2004.

Codo, Wanderley \& SoRATo, Lúcia. Trabalho: atividade humana por excelência. In: Codo, Wanderley (coord.). Educação: carinho e trabalho (Burnout, a síndrome da desistência do educador, que pode levar à falência da educação). Petrópolis: Vozes; Brasília: Confederação Nacional dos Trabalhadores em Educação: Universidade de Brasília. Laboratório de Psicologia do Trabalho, 1999.

Codo, Wanderley \& Vasques-Menezes, lône. Educar, educador. In: CODO, Wanderley (coord.). Educação: carinho e trabalho (Burnout, a síndrome da desistência do educador, que pode levar à falência da educação). Petrópolis: Vozes; Brasília: Confederação Nacional dos Trabalhadores em Educação: Universidade de Brasília. Laboratório de Psicologia do Trabalho, 1999.

CORETH, Emerich. Questões fundamentais de hermenêutica. São Paulo: EPU-Universidade de São Paulo, 1973.
Coutinho, Aldacy Rachid. Trabalho e pena. Revista da Faculdade de Direito da UFPR, v. 32, n. 0, p. 723, Curitiba, 1999.

Dupas, Gilberto. Economia global e exclusão social. São Paulo: Paz e Terra, 1999.

Gorz, André. Crítica da divisão do trabalho. São Paulo: Martins Fontes, 1980.

Adeus ao proletariado. Rio de Janeiro: Forense Universitária, 1982.

Harman, Willis \& HoRmann, John. O trabalho criativo: o papel construtivo dos negócios numa sociedade em transformação. São Paulo: Cultrix, 1997.

LAfER, Celso. A política e a condição humana. In: Arend, Hannah. A condição humana. Rio de Janeiro: Forense Universitária, 2004.

PAstore, José. O alcance do trabalho prisional. O Estado de S. Paulo, São Paulo, 22 de maio de 2001.

Richardson, Roberto Jarry. Pesquisa social: métodos e técnicas. São Paulo: Atlas, 1999.

SILva, Roberto da. O que as empresas podem fazer pela reabilitação do preso. São Paulo: Instituto Ethos, 2001.

Triviños, Augusto Nibaldo Silva. Introdução à pesquisa em ciências sociais: a pesquisa qualitativa em educação. São Paulo: Atlas, 1987. 